\title{
Short and long-term determinants of social detachment in later life
}

Stephen Jivraj ${ }^{1}$, James Nazroo ${ }^{2}$, Matt Barnes ${ }^{3}$

${ }^{1}$ Department of Epidemiology and Public Health, University College London, London WC1E 6BT, United Kingdom

${ }^{2}$ Sociology and Cathie Marsh Institute for Social Research, University of Manchester, Manchester, M13 9PL, UK

${ }^{3}$ Department of Sociology, City University London, London, EC1V OHB, UK

stephen.jivraj@ucl.ac.uk

\section{Abstract}

The benefits of engagement with social activities on health and wellbeing are widely reported by gerontologists. Less is known, however, what drives withdrawal from and reengagement with social activities in later life. This is an important area of research that has direct implications for public policies that aim to ensure equitable outcomes among older adults. Much of the existing literature supports continuity theory which assumes people will not alter their level of social engagement as they age or after life changing events. This paper uses data from the English Longitudinal Study of Ageing over an eight-year period (2002-2010) to determine the effect of short-term changes in marital, employment and health status over an initial four-year period on the dynamics of social detachment over the following four years. We control for underlying socioeconomic disadvantages built up during the life course and find that these effects, including poor education, wealth and health, are the most important determinants of persistent detachment from social activities as well as movement into and out of social detachment. The effects are consistent in men and women. The effects of short-term changes in marital and employment status have little effect on social detachment. Recent deterioration in health, however, predicted movement into social detachment, which implies the relationship between health and social detachment is reciprocal.

Keywords: social detachment, social activity, continuity theory, cumulative advantage, socioeconomic inequalities, English Longitudinal Study of Ageing. 


\section{Introduction}

There is a flourishing literature indicating the benefits of social activity in later life on health and wellbeing, or to what gerontologists refer to as successful ageing. The effect of social engagement on successful ageing has its foundations in activity theory. It suggests that wellbeing is fostered by an active lifestyle which can provide an antidote to the loss of productive roles that are relinquished after retirement (Adams, Leibbrandt and Moon 2010; Silverstein and Parker 2002; Thanakwang and Isaramalai 2013). Activity theory assumes that participation in social activities fulfil basic human needs for social interaction and affiliation (Jang and Chiriboga 2011). A number of studies have shown that subjective wellbeing is significantly higher in older adults who are socially active (BalboaCastillo, León-Muñoz, Graciani, Rodríguez-Artalejo and Guallar-Castillón 2011; Hawkins, Foose, Binkley and Binkley 2004; Jenkins 2011; Nimrod 2007; Onishi et al. 2006; Silverstein and Parker 2002; Simone and Haas 2013).

It is also becoming widely accepted by researchers and policymakers that the counterfactual, social detachment has a detrimental effect on various aspects of physical and mental health in later life. Older people who are withdrawn from social activities are shown to be at greater risk of mortality (Agahi and Parker 2008; Saito, Kondo, Kondo, Ojima and Hirai 2012; Steptoe, Shankar, Demakakos and Wardle 2013), disability (James, Boyle, Buchman and Bennett 2011; Lund, Nilsson and Avlund 2010; Mendes de Leon 2003), depression (Chiao, Weng and Botticello 2011; Jang and Chiriboga 2011; Prieto-Flores, Forjaz, Fernandez-Mayoralas, Rojo-Perez and Martinez-Martin 2011) and cognitive decline (Andrew and Rockwood 2010; Bassuk, Glass and Berkman 1999; James, Wilson, Barnes and Bennett 2011; Krueger et al. 2009; Niti, Yap, Kua, Tan and Ng 2008; Thomas 2011b). It is therefore important to uncover the drivers of withdrawal from social activity. This study will explore the dynamics of social detachment and the associated changes in later life, such as retirement, widowhood and declining health. 
The paper is structured as follows. The next section explores theories on the benefits of social engagement and the dynamics of social activity in later life before evaluating the empirical evidence. The following section explains the data and methods used. Section four presents the results and section five draws conclusions.

\section{Benefits of social engagement in older adults}

There are a number of causal pathways through which the effect of social engagement has been theorised, including psychological, physiological and behavioural. Social integration theory suggests that social engagement can provide a sense of purpose which may be lacking in older age as people move into retirement and away from paid work (Agahi and Parker 2008; Thomas 2011b). The replacement of time spent at work with more leisure-orientated activities in later life may ensure the psychological benefit of social engagement is sustained. Social activity can also affect physical and mental health outcomes by enabling people to deal with emotional feelings and improving coping abilities to stressful situations (Kim, Kim and Kim 2013; Kouvonen et al. 2012; Wang, Xu and Pei 2012). Social activity that requires physical exertion can improve physiological functions such as cardiovascular health and immune function (Agahi and Parker 2008). Physically orientated social activity such as exercise has been shown to have a stronger effect on cognition (Wang et al. 2012) and self-perceived quality of life (Balboa-Castillo et al. 2011) than sedentary activity.

Interaction with social contacts in various situations can provide support which encourages people to exchange health information, seek medical treatment for emerging health conditions, adhere to medication for existing health problems and participate less in negative health behaviours (Coyle and Dugan 2012; Fothergill et al. 2011; Kouvonen et al. 2012; Stephens, Alpass, Towers and Stevenson 2011). This is supported by evidence that suggests that informal activities have a greater effect on subjective wellbeing as compared with formal activities. Formal activities may not provide the same opportunity to exchange health information and support (Adams et al. 2010; Ekström, 
Dahlin Ivanoff and Elmståhl 2013; Jenkins 2011). There is evidence, however, to suggest that the effect of social activity extends beyond social control of health behaviours that are influenced by social networks. This is because health behaviours, including smoking cigarettes and alcohol consumption, do not fully mediate the effect of social interaction on outcomes such as mortality (Luo, Hawkley, Waite and Cacioppo 2012).

It is likely that psychological, physiological and behavioural pathways are inter-related and that their importance is dependent on the type of social activity engaged in. There is also evidence to suggest that there are strong gender differences in the effect of social activities. Socially engaged women are shown to have a lower mortality risk (Agahi and Parker 2008; Saito et al. 2012), slower cognitive decline (Thomas 2011a) and better subjective wellbeing (Jenkins 2011) than socially engaged men. In contrast, the protective effects of social activity on the onset of disability is stronger in men compared with women (James et al. 2011; Lund et al. 2010). James et al. (2011) speculate that lower social activity among men may act as an indicator of impending disability and therefore reverse causality cannot be ruled out. This supports Thomas' (2011a) finding that physical and cognitive limitations in men lead to lower levels of subsequent engagement, whereas for women the flow is from greater social engagement to lower levels of physical and cognitive declines.

\section{Change in social detachment in later age}

Social disengagement theory posits that as people age they will gradually withdraw from social activities (Fothergill et al. 2011). The empirical evidence provides little support for an independent effect of ageing on social detachment, except at the oldest age. There is more support for continuity theory, which suggests that as people age they attempt to maintain the roles and activity patterns that were established earlier in their lives (Donnelly and Hinterlong 2010). Agahi et al. (2006) use Swedish longitudinal data over a 34-year period and find that engagement in leisure activities in middle age has a strong effect on engagement in older age. There is further evidence to suggest that 
social engagement remains constant in spite of transitions common in later life, such as widowhood and retirement, providing support for continuity theory. Donnelly and Hinterlong (2010) compared formal participation in social and religious groups as well as informal social participation with friends and relatives in a US sample of people aged 60 and over. They found that recently widowed older adults were likely to remain engaged in informal activities, but not formal activities. A similar conclusion is drawn by Utz et al. (2002).

Scherger et al. (2010) find that older adults in England continue their leisure activities over a two year period regardless of changes in work and chronological age. The only exception is for those who stop work because of an illness. They did find that a decline in self-reported health predicts both a higher likelihood of starting and ending involvement in cultural leisure activities, which includes going to the cinema, a concert, opera or theatre performances and to museums. Strain et al. (2002) find a similar effect in a Canadian sample of people aged 60 to 85 over an eight-year period. Involvement in leisure activities was less likely at follow-up for those who reported poorer self-rated health and more functional disabilities over time.

A sociological criticism of continuity theory is that it simply explains the cumulative advantages or disadvantages developed during the life course rather than an innate disposition to be socially active at all stages of life (Marshall and Bengtson 2011). Older people who have been socially and economically successful throughout their life are able to maintain their involvement because of confidence developed to deal with social settings and because of wealth they have accumulated which enables participation (Scherger et al. 2010). Such a view is supported by the evidence that shows those most likely to remain socially engaged in later life and less likely to become socially detached, are those with a higher socioeconomic status and better self-rated health (Cornwell and Waite 2009; Ibrahim, Abolfathi Momtaz and Hamid 2013; Jivraj, Nazroo and Barnes 2012; Strain et al. 2002; Villar 2011). These findings suggest that successful ageing is not something that people can decide to do after retirement. This is because social engagement is intrinsically linked with outcomes 
during the life course which cumulatively lead to greater inequalities in later life (Stowe and Cooney 2014; Youssim, Hank and Litwin 2014).

This study will test the effect of accumulated disadvantages, such as socioeconomic inequalities, as well as short-term changes in status, including retirement, to identify determinants of sustained detachment, recent detachment and renewed engagement in social activity. The analysis is separated for men and women, because of the expected differential effect of gender on social detachment. We hypothesis that underlying socioeconomic inequalities will be the main drivers of sustained detachment and changes in social detachment and that these effects will be equally important in women and men. However, we expect that recent changes in marital status, especially recent widowhood and health status will have an independent effect, but have differential effects in men and women. The findings will interest policymakers who wish to tackle the negative effects of detachment by mediating the risk factors of withdrawal from social activity as well as addressing structural inequalities that sustain lifetime disadvantages.

\section{Data and methods}

We use data from the English Longitudinal Study of Ageing (ELSA) at wave one (2002-03), wave three (2006-07) and wave five (2010-11). ELSA is a panel study of people living in private households aged 50 and over, which first collected information in 2002-03 when respondents who had previously taken part in the Health Survey for England were re-interviewed (Steptoe, Breeze, Banks and Nazroo 2012). The sample members have been interviewed face to face and asked to complete a selfcompletion questionnaire biennially. At wave one a response rate of 67 per cent $(11,391$ respondents) was achieved and by wave five a response rate of 55 per cent $(6,242$ respondents) was achieved of those sampled at wave one. 42 per cent of those who did not respond had died, moved out of Britain or into an institution. The data are adjusted in this study using a longitudinal weighting factor that was calculated for the 5,315 respondents who responded to all five waves of ELSA and 
remained living in a private household. The weighting factor ensures the sample is representative of the population aged 50 and over in 2002 by adjusting for the characteristics of those who were more likely to respond at all five waves.

\section{Measuring social detachment}

ELSA asked about engagement in a range of itemised social activities from formal membership of organisations to informal contact with family and friends. We use selected items to form a composite index that identifies whether a person is detached from social activity. For this we use a cut-off of fewer than three activities out of 12 to indicate social detachment. We exclude activities that are common everyday experiences (e.g. watching television) to ensure we do not only identify those people who experience extreme forms of social detachment and concentrate on those items that require some form of social interaction that the literature suggests has a positive effect on health and wellbeing outcomes (Agahi and Parker 2008; Jenkins 2011b; Lund et al. 2010).

Figure 1 shows that more than a quarter of men and women are engaged with fewer than three social activities at wave three and hence defined as socially detached. There are four per cent of men and women who were not engaged in any of the social activities described below.

Items included in the index are membership of a religious group; attendance at at least one committee meetings for a membership organisation, club or society in a year; volunteering at least once in the last year; membership of a social, education, arts or music group, sports club, gym or exercise class; going to the cinema, art gallery, museum, theatre, concert or opera at least once in the last year; meeting in person a child, family member or friend at least once a week, on average. If a person has participated in at least three of these activities, they are not considered socially detached. The items in the composite index have been used in a number of other studies using the ELSA dataset and have been shown to be associated with measures of social isolation, loneliness and 
other health outcomes (Jivraj et al. 2012; Shankar, McMunn, Banks and Steptoe 2011; Steptoe et al. 2013). In using a cut-off we provide no indication of the severity of social detachment.

Table 1 shows the proportion of respondents engaged in each activity in the social detachment index at wave three. The most common social activities are meeting with friends and children, which more than half of respondents did once a week. Women are much more likely to meet with social contacts and in particular family members, than men. The least common social activities are membership of groups, especially those orientated to the arts. Women, however, are twice as likely to be members of an arts club compared with men. A higher proportion of men and women went to a see a form of cultural entertainment (e.g. cinema), at least once during the last year than were members of cultural groups (e.g. arts club). Women are also more likely to be a member of a church or do voluntary work. One in six men are a member of a church group compared with more than one in four women.

Change in social detachment is measured between 2006 (wave three) and 2010 (wave five) and grouped into four categories: not detached in both waves, detached in both waves, becomes detached and no longer detached. Table 2 shows the change in social detachment between wave three and wave five for respondents with four or fewer missing items on the social detachment index. More than a fifth of respondents became detached or no longer detached from social activity. The balance of change in men and women is in favour of movement into social detachment rather than out of social detachment with almost 50 per cent fewer making the latter transition. Among those respondents who did not change their detachment status, men are more likely than women to remain detached from social activity.

\section{Statistical analysis}


Models are fitted for change in social detachment to determine the independent effect of explanatory variables separately for men and women. Multinomial logistic regression models are used to take account of the four different transitions in social detachment that an individual could have made (i.e. not detached in both waves, detached in both waves, becomes detached, and becomes no longer detached). The explanatory variables are derived from factors shown to be important in the literature (see Table 3). They include both time varying and non-time varying covariates and are described below.

The time constant covariates measured at wave one are age group, non-pension household wealth quintile, education level, subjective health status, place of residence (urban, town or rural) and access to a car. Access to a car is measured by having use of a car or van either as a passenger or driver. Place of residence is determined using a neighbourhood-level classification of rurality. Wealth (quintiles) and health status (very good to very bad) are added to the model as linear effects after descriptive analyses showed them to have linear relationships with the outcome response categories.

The time varying covariates, measured at waves one and three, are marital, employment and health status. Change in marital status during a four year period is coded: in a couple in both waves; single and never married in both waves; separated in both waves; widowed in both waves; become coupled; become separated; or become widowed. Change in employment status during the same period is coded: retired and not working in both waves; working full time or part time in both waves; other (i.e. unemployed, permanently sick or looking after family) in both waves; retired from working; retired from other; working from other or retired; or other from working or retired. Change in health status is derived by subtracting health status in wave three from health status in wave one, which, if higher, indicates declining subjective health. 
A methodological challenge when using multi-item scales, such as a social detachment index, in regression analysis and including numerous explanatory variables is that missingness can substantially reduce the sample size. This can lead to biased results if there is selective non-response (White, Royston and Wood 2011). This is because the analysis is only conducted on complete cases, which refers to respondents who have a value for all variables. Multiple imputation, which can provide predicted values for missing cases using information from the variables included in a model of interest as well as other related to the missingness, is becoming a widely used technique to take account of missing data. The technique has been shown to be more efficient and provide less biased results than complete case analysis or other rudimentary methods of imputation, including adding dummy variables to missing values or replacing missings with mean values. In this study, we use multiple imputation followed by deletion of cases where the outcome variable is missing. The social detachment outcome variable is missing in 1,290 of the 5,315 sample members that responded to ELSA waves one to five. Von Hippel (2007) shows that using imputed outcome variables can add noise to the model estimates. Five imputations are generated for missing data using all of the variables in the final models of interest. The Stata $12 \mathrm{mi}$ command was used to combine completed data-analysis on each imputation to provide single estimates (StataCorp 2011). The imputed results are substantively similar when compared with a complete case analysis.

\section{Results}

Table 4 shows the association between change in social detachment and covariates using relative risks of being detached in both wave three and wave five, becoming detached by wave five and becoming no longer detached by wave five, compared to the reference category of those not being detached in both wave three and wave five. The multinomial logistic regressions are adjusted for all covariates in the model and fitted separately for women and men. Models adjusting for age only had similar effects. 
The model results indicate that older age, less education, lower wealth, poorer health and living in a rural area are independent risk factors of being consistently detached from social activities. Men and women aged over 70 were considerably more likely to remain detached from social activities than those who were younger. The same is true of those with low education compared to those with medium or high education, particularly among women. The risk of being continually detached is less than a fifth of that for those women with a degree compared to those with no qualifications. Declining self-reported health is also associated with a higher likelihood of being consistently detached from social activity.

Men who were single and never married are much more likely to remain socially detached than those who were in a couple. Women who have been widowed for some time and, in particular, those who were recently widowed are less likely to remain detached from social activities. It is not surprising that men and women who remained in employment are at higher risk of being consistently socially detached. This could be a consequence of having less free time to participate in social activities. Models adjusting only for age show that men and women who were not working or retired (i.e. unemployed, permanently sick or looking after family) and who did not have access to a car are at greater risk of persistent social detachment (analysis not shown here). These effects are explained by wealth and health status in the fully-adjusted models.

The influences of change in social detachment, whether becoming detached or becoming no longer detached, are similar to those that predicted persistent detachment. Having low education, lower wealth and poorer health are each independently associated with becoming detached and becoming no longer detached in men and women. This suggests that those with these characteristics have a difficulty in maintaining involvement in social activity. There were other effects on change in social detachment that are specific to movement into or out of detachment. Men and women with declining health are at risk of becoming socially detached. Being employed in wave one and wave 
three is associated with a higher likelihood of moving out of social detachment between wave three and wave five, but does not increase or decrease the risk of becoming socially detached.

There are also gender specific effects on change in social detachment. Men living in rural areas are more likely to move into social detachment compared with those living in urban areas. Being without access to a car was associated with movement into and out of detachment in men, but not women. Older women are at greater risk of becoming detached than those aged below 70 . Women who had been separated for some time and men who were recently separated are less likely to move into social detachment. Men who stopped working because of unemployment, illness or family responsibilities are less likely to move out of social detachment than those who were retired, whereas those who were in employment are more likely to move out of social detachment. There were no other significant effects of transitions in marital or employment status on change in social detachment. This may be due to the small number of individuals in some of the categories of marital status and employment status change.

\section{Discussion}

This study uses longitudinal data to examine the effect on change in social detachment of underlying social inequalities and short-term prior changes in marital, employment and health status. We hypothesise that long-standing socioeconomic and health disparities in older adults drive persistent detachment from social activities as well as withdrawal from social activities over time. The findings show that inequalities in wealth, education and health predict persistent detachment from social activities, but also movement into and out of social detachment and that these effects are consistent in men and women. This suggests that disadvantaged older adults find it difficult to engage in and stay engaged in social activities and that renewed engagement might reflect an insecurity of engagement of those who want to be socially active but cannot afford to keep it up. This insecurity could be brought about by those who experience long-term disadvantages relying on extended 
family and friends to transport them to social activities, for example, rather than an effect of shortterm improvements in health or changes in marital or employment status. These disadvantages may stem from not having the financial or physical capability to attend social activities as well as the confidence required to engage with others in a social setting. The capacities required to remain consistently engaged in social activities are likely to have been built-up during the life course through a process of cumulative advantage and therefore difficult to reverse in later life.

Changes in marital and employment status are not shown to have clear effects on change in social detachment when controlling for underlying socioeconomic and health inequalities. This suggests that experience of common transitions in later life, such as retirement and widowhood, are not the cause of disengagement from social activity. However, there are specific gender effects on persistent detachment. Women who are not in a couple, especially recent widows, had a lower risk of being consistently detached from social activity than those in a couple. It could be the case that recent widows are provided with the support to engage in social activity from friends and family (Donnelly and Hinterlong 2010). Furthermore, these women might have been relieved of caring responsibility following the death of their partner, which enables them to engage in social activities. In contrast, men who were single and never married are considerably more likely to be consistently detached from social activity than those in a couple. Men might find it more difficult to engage socially with other people they do not know than women, because women appear much more able and willing to meet with friends and their extended family (Antonucci and Akiyama 1987; James et al. 2011).

There is an effect of declining health status on continual social detachment and withdrawal from social activity in men and women. There is no effect, however, on movement out of detachment as a result of declining health, which suggests a one-way process of deteriorating health leading to persistently less social engagement. This does not mean that there is not a reverse effect of less social activity on health, but that older adults who experience health declines are unlikely to reengage with social activity. It might well be the case that withdrawal from social activity 
compounds deterioration in health. The longitudinal data used in our analysis enables us to separate the timing of change in independent variables from change in dependent variables, which helps with the ability to deal with bidirectional causation. Nonetheless, we will almost certainly underestimate the size of causal effects and perhaps fail to identify some causal associations because of the short duration over which we measure change and the impact of any lagged effect.

Unexpectedly, age had an independent effect on continual social detachment and, in women, withdrawal from social activity. This could be a consequence of deteriorating health that is not adequately captured by self-rated health. We tested measures, at baseline and over time, in morbidity and disability to see whether objective measures of health had an effect over and above self-rated health. However, the inclusion of a disability or a limiting illness and change over time in these effects did not have a significant association with social detachment and did not alter the power of the age effect in the model.

Older adults living in a rural area had a greater risk of being socially detached than those living in urban areas. Rural living has been shown to be a risk factor of social detachment in other studies (Ekström et al. 2013; Ibrahim et al. 2013). This is likely to reflect the fact that fewer social opportunities are available in rural areas, because there are fewer people and places to visit, which also means people are more vulnerable to becoming socially detached. Access to facilities will also be more difficult for those living in rural areas and may deter people from engaging socially even when they have means of transport. This is substantiated by the fact that there was not a significant effect of access to transport on social detachment in women.

There are number of factors that limit the findings of this study. The measurement of social detachment is derived from participation in a range of social activities in ELSA. The items used in this study carry equal weight and form one composite index. It is unclear for some of the indicators how often people engaged or whether they are active or passive participants. Membership of religious, 
arts, sports and social organisations are items used in the composite index, however, the question in the ELSA self-completion questionnaire does not ask how frequently respondents attend or how socially active they are when they are at meetings for these groups. This will matter if only regular and active participation provides the necessary benefit from social activity to ensure successful ageing.

The literature on the benefits of social engagement does suggest that informal social activities are more important in terms of fostering positive later life health and wellbeing outcomes compared to formal activities (Adams et al. 2010; Chiao et al. 2011; Ekström et al. 2013). However, Simone and Haas (2013) suggest that what is most important is whether the activity is socially-based. There is further evidence to suggest that engagement across a wide range of social activities is related to positive outcomes in later life (James et al. 2011; Löckenhoff, Cook anderson and Zayas 2013; Saito et al. 2012; Thomas 2011b). The inconclusive findings from the literature are, in part, a consequence of the many different ways social activity has been measured. More research is therefore required to determine what forms of social activity are most important in terms of ensuring successful ageing. Moreover, it might also be important to separate the types of activity when measuring the determinants of social detachment. Other studies have split domains of social activity and found that the determinants of informal social activities are different to formal and other leisure-based activities (Jivraj et al. 2012).

A technical limitation of this study is the level of missingness in the outcome variable. A thousand cases were lost due to respondents not completing the ELSA self-completion questionnaire in its entirety or in particular items that comprised the social detachment index. Those who are missing were more likely to be older, with low education, poorer, unhealthy and not retired. Therefore, assuming those who are missing would be more likely to be socially detached, the effect of bias in these missing cases would temper the effect of the determinants found to be independently associated with social detachment. 
Another limitation of the data are the small number of respondents who made uncommon changes in their marital status, including forming a new partnership or separating from an existing partner. This makes it difficult to estimate how likely people who became separated or coupled are to withdraw from or engage with social activities. However, shortening the period of change to limit the effect of attrition or measuring change in status over a longer period to ensure a larger number of respondents in each change category did not affect the substantive findings.

Taking into account these limitations, the findings from this study should be used to inform policy to tackle the drivers of social detachment and withdrawal from social activity that is more likely to affect older people facing socioeconomic and health disadvantages. This is important because engagement in social activity is clearly linked to successful ageing (Adams et al. 2010). Many of the consequences of later life detachment from social activity, including premature morbidity and mortality appear to be intertwined with other determinants of negative later life outcomes. Nonetheless, there are interventions that could be made to mediate the effects of social detachment and counterbalance the risks of moving into detachment and help those able to reengage, to stay engaged.

A criticism of the policy agenda is that the focus is now almost entirely on encouraging people to work longer, without not giving the same priority to interventions aimed at social engagement that benefit both individuals and wider society. For example, in England the core theme of the Department for Work and Pensions Improving opportunities for older people policy is centred on enabling people to stay in work for longer. While there have been programmes oriented towards enabling participation in social activities, including Active at 60 , these have been one-off and afforded limited funding and political support. This is despite of the success of these programmes in delivering increased opportunities for older people and improving their mental wellbeing (Hatamian, Pearmain and Golden 2012). The findings from this paper suggest that these programmes are best 
targeted at those older adults who have experienced sustained disadvantage over the life course and recent declines in health rather than those who have experienced short-term changes in employment or marital status.

\section{Acknowledgements}

This research was supported by funding for the English Longitudinal Study of Ageing, which is provided by the National Institute of Aging (grants 2RO1AG7664-01A1 and 2RO1AG017644) and a consortium of UK government departments coordinated by the Office for National Statistics. We would like to thank Benjamin Tse for his help searching for the papers in the literature review. 


\section{References}

Adams, K. B., Leibbrandt, S. and Moon, H. 2010. A critical review of the literature on social and leisure activity and wellbeing in later life. Ageing and Society, 31, 4, 683-712.

Agahi, N., Ahacic, K. and Parker, M. G. 2006. Continuity of leisure participation from middle age to old age. The Journals of Gerontology. Series B, Psychological Sciences and Social Sciences, 61, 6, S340-6.

Agahi, N. and Parker, M. G. 2008. Leisure activities and mortality: does gender matter? Journal of Aging and Health 20, 7, 855-71.

Andrew, M. K. and Rockwood, K. 2010. Social vulnerability predicts cognitive decline in a prospective cohort of older Canadians. Alzheimer's and Dementia: The Journal of the Alzheimer's Association, 6, 4, 319-25.

Antonucci, T. and Akiyama, H. 1987. An examination of sex differences in social support among older men and women. Sex Roles, 17, 11-12, 737-49.

Balboa-Castillo, T., León-Muñoz, L. M., Graciani, A., Rodríguez-Artalejo, F. and Guallar-Castillón, P. 2011. Longitudinal association of physical activity and sedentary behavior during leisure time with health-related quality of life in community-dwelling older adults. Health and Quality of Life Outcomes, 9, 47, 1-10.

Bassuk, S., Glass, T. and Berkman, F. 1999. Social disengagement and incident cognitive decline in community-dwelling elderly persons. Annals of Internal Medicine, 131, 3, 165-73.

Chiao, C., Weng, L.-J. and Botticello, A. L. 2011. Social participation reduces depressive symptoms among older adults: an 18-year longitudinal analysis in Taiwan. BMC Public Health, 11, 292, 119. 
Cornwell, E. Y. and Waite, L. J. 2009. Measuring Social Isolation Among Older Adults Using Multiple Indicators From the NSHAP Study, 38-46. Journal of Gerontology: Social Sciences, 64B, 1, i38i46

Coyle, C. E. and Dugan, E. 2012. Social isolation, loneliness and health among older adults. Journal of Aging and Health, 24, 8, 1346-63.

Donnelly, E. a and Hinterlong, J. E. 2010. Changes in social participation and volunteer activity among recently widowed older adults. The Gerontologist, 50, 2, 158-69.

Ekström, H., Dahlin Ivanoff, S. and Elmståhl, S. 2013. Does informal support influence social participation of fractured elderly people? Archives of Gerontology and Geriatrics, 56, 3, 457-65.

Fothergill, K. E., Ensminger, M. E., Robertson, J., Green, K. M., Thorpe, R. J. and Juon, H. S. 2011. Effects of social integration on health: A prospective study of community engagement among African American women. Social Science and Medicine, 72, 2, 291-8.

Hatamian, A., Pearmain, D. and Golden, S. 2012. Outcomes of the Active at 60 Community Agent Programme. Department for Work and Pensions Research Report No 808, London.

Hawkins, B., Foose, A. K. and Binkley, A.L. 2004. Contribution of Leisure to the Life Satisfaction of Older Adults in Australia and the United States. World Leisure Journal, 46, 2, 4-12.

Ibrahim, R., Abolfathi Momtaz, Y. and Hamid, T. A. 2013. Social isolation in older Malaysians: prevalence and risk factors. Psychogeriatrics : The Official Journal of the Japanese Psychogeriatric Society, 13, 2, 71-9.

James, B. D., Boyle, P. a, Buchman, A. S. and Bennett, D. A. 2011. Relation of late-life social activity with incident disability among community-dwelling older adults. The Journals of Gerontology. Series A, Biological Sciences and Medical Sciences, 66, 4, 467-73. 
James, B. D., Wilson, R. S., Barnes, L. L. and Bennett, D. A. 2011. Late-life social activity and cognitive decline in old age. Journal of the International Neuropsychological Society, 17, 6, 998-1005.

Jang, Y. and Chiriboga, D. A. 2011. Social activity and depressive symptoms in Korean American older adults: the conditioning role of acculturation. Journal of Aging and Health, 23, 5, 767-81.

Jenkins, A. 2011. Participation in learning and wellbeing among older adults. International Journal of Lifelong Education, 30, 3, 403-20.

Jivraj, S., Nazroo, J. and Barnes, M. 2012. Change in social detachment in older age in England. In Banks, J., Nazroo, J. and Steptoe, A. (eds), The Dynamics of Ageing: Evidence from the English Longitudinal Study of Ageing 2002-10 (Wave 5), Institute for Fiscal Studies, London, 49-97.

Kim, J., Kim, M. and Kim, J. 2013. Social Activities and Health of Korean Elderly Women by Age Groups. Educational Gerontology, 39, 9, 640-54.

Kouvonen, A., Swift, J. A., Stafford, M., Cox, T., Vahtera, J., Väänänen, A., Heponiemi, T., De Vogli, R., Griffiths, A. and Kivimäki, M. 2012. Social participation and maintaining recommended waist circumference: prospective evidence from the english longitudinal study of aging. Journal of Aging and Health, 24, 2, 250-68.

Krueger, K. R., Wilson, R. S., Julia, M., Barnes, L. L., Bienias, J. L. and Bennett, D. A. 2009. Social Engagement and Cognitive Function in Old Age. Experimental Aging Research, 35, 1, 45-60.

Löckenhoff, C. E., Cook, M. a anderson, J. F. and Zayas, V. 2013. Age differences in responses to progressive social exclusion: the role of cognition and socioemotional functioning. The Journals of Gerontology. Series B, Psychological Sciences and Social Sciences, 68, 1, 13-22.

Lund, R., Nilsson, C. J. and Avlund, K. 2010. Can the higher risk of disability onset among older people who live alone be alleviated by strong social relations? A longitudinal study of non-disabled men and women. Age and Ageing, 39, 3, 319-26. 
Luo, Y., Hawkley, L. C., Waite, L. J. and Cacioppo, J. T. 2012. Loneliness, health and mortality in old age: a national longitudinal study. Social Science and Medicine, 74, 6, 907-14.

Marshall, V. and Bengtson, V. 2011. Theoretical Perspectives on the Sociology of Aging. In R. A. Settersten, R. A. and Angel, J. L. (eds), Handbook of Sociology of Aging, Springer, New York, 1733.

Mendes de Leon, C. F. 2003. Social Engagement and Disability in a Community Population of Older Adults: The New Haven EPESE. American Journal of Epidemiology, 157, 7, 633-42.

Nimrod, G. 2007. Retirees' Leisure: Activities, Benefits and their Contribution to Life Satisfaction. Leisure Studies, 26, 1, 65-80.

Niti, M., Yap, K.-B., Kua, E.-H., Tan, C.-H. and Ng, T.-P. 2008. Physical, social and productive leisure activities, cognitive decline and interaction with APOE-epsilon 4 genotype in Chinese older adults. International Psychogeriatrics 20, 2, 237-51.

Onishi, J., Masuda, Y., Suzuki, Y., Gotoh, T., Kawamura, T. and Iguchi, A. 2006. The pleasurable recreational activities among community-dwelling older adults. Archives of Gerontology and Geriatrics, 43, 2, 147-55.

Prieto-Flores, M.-E., Forjaz, M. J., Fernandez-Mayoralas, G., Rojo-Perez, F. and Martinez-Martin, P. 2011. Factors associated with loneliness of noninstitutionalized and institutionalized older adults. Journal of Aging and Health, 23, 1, 177-94.

Saito, M., Kondo, N., Kondo, K., Ojima, T. and Hirai, H. 2012. Gender differences on the impacts of social exclusion on mortality among older Japanese: AGES cohort study. Social Science and Medicine, 75, 5, 940-5.

Scherger, S., Nazroo, J. and Higgs, P. 2010. Leisure activities and retirement: do structures of inequality change in old age? Ageing and Society, 31, 1, 146-72. 
Shankar, A., McMunn, A., Banks, J. and Steptoe, A. 2011. Loneliness, social isolation and behavioral and biological health indicators in older adults. Health Psychology : Official Journal of the Division of Health Psychology, American Psychological Association, 30, 4, 377-85.

Silverstein, M. and Parker, M. G. 2002. Leisure Activities and Quality of Life among the Oldest Old in Sweden. Research on Aging, 24, 5, 528-47.

Simone, P. M. and Haas, A. L. 2013. Frailty, Leisure Activity and Functional Status in Older Adults: Relationship With Subjective Well Being. Clinical Gerontologist, 36, 4, 275-93.

StataCorp. 2011. Stata Statistical Software: Release 12. StataCorp LP, Texas.

Stephens, C., Alpass, F., Towers, A. and Stevenson, B. 2011. The effects of types of social networks, perceived social support and loneliness on the health of older people: accounting for the social context. Journal of Aging and Health, 23, 6, 887-911.

Steptoe, A., Breeze, E., Banks, J. and Nazroo, J. 2013. Cohort Profile: The English Longitudinal Study of Ageing (ELSA). International Journal of Epidemiology, 42, 6, 1640-8.

Steptoe, A., Shankar, A., Demakakos, P. and Wardle, J. 2013. Social isolation, loneliness and all-cause mortality in older men and women. Proceedings of the National Academy of Sciences of the United States of America, 110, 15, 5797-801.

Stowe, J. D. and Cooney, T. M. forthcoming. Examining Rowe and Kahn's Concept of Successful Aging: Importance of Taking a Life Course Perspective. The Gerontologist.

Strain, L. a, Grabusic, C. C., Searle, M. S. and Dunn, N. J. 2002. Continuing and ceasing leisure activities in later life: a longitudinal study. The Gerontologist, 42, 2, 217-23.

Thanakwang, K. and Isaramalai, S.-A. 2013. Productive engagement in older adults: a concept analysis. Nursing and Health Sciences, 15, 1, 124-30. 
Thomas, P. A. 2011a. Gender, social engagement and limitations in late life. Social Science and Medicine 1982, 73, 9, 1428-35.

Thomas, P. A. 2011b. Trajectories of social engagement and limitations in late life. Journal of Health and Social Behavior, 52, 4, 430-43.

Utz, R. L., Carr, D., Nesse, R. and Wortman, C. B. 2002. The effect of widowhood on older adults' social participation: an evaluation of activity, disengagement and continuity theories. The Gerontologist, 42, 4, 522-33.

Villar, F. 2011. Successful ageing and development: the contribution of generativity in older age. Ageing and Society, 32, 7, 1087-1105.

Von Hippel, P. T. 2007. Regression with missing Y's: an improved strategy for analyzing multiply imputed data. Sociological Methodology, 37, 1-54.

Wang, H.-X., Xu, W. and Pei, J.-J. 2012. Leisure activities, cognition and dementia. Biochimica et Biophysica Acta, 1822, 3, 482-91.

White, I. R., Royston, P. and Wood, A. M. 2011. Multiple imputation using chained equations: Issues and guidance for practice. Statistics in Medicine, 30, 4, 377-99.

Youssim, I., Hank, K. and Litwin, H. forthcoming. The Role of Family Social Background and Inheritance in Later Life Volunteering: Evidence From SHARE-Israel. Research on Aging. 


\section{Tables and Figures}

Table 1. Participation in social activities, wave 3 (2006/07)

\begin{tabular}{lrrr}
\hline & Men (\%) & Women (\%) & All (\%) \\
\cline { 2 - 4 } Church or religious group & 17.0 & 26.0 & 21.9 \\
Voluntary work & 26.9 & 28.8 & 27.9 \\
Committee meeting & 38.8 & 31.4 & 34.6 \\
& & & \\
Education, arts or music group or class & 9.0 & 14.5 & 12.0 \\
Sports club, gym or exercise class & 20.0 & 20.9 & 20.5 \\
Art gallery or museum & 40.3 & 38.9 & 39.5 \\
Theatre, concert or opera & 44.1 & 53.2 & 49.0 \\
Cinema & 35.3 & 40.2 & 38.0 \\
Social club & 23.7 & 18.2 & 20.7 \\
& & & \\
Meet family & 29.3 & 36.8 & 33.5 \\
Meet children & 55.5 & 61.0 & 58.5 \\
Meet friends & 55.3 & 59.8 & 57.8 \\
\hline
\end{tabular}

Table 2. Change in social detachment, wave 3 - wave 5 (2006/07-2010/11)

\begin{tabular}{lrrr}
\hline & Men (\%) & Women (\%) & All (\%) \\
No detachment & 56.7 & 61.5 & 59.4 \\
Consistently detached & 20.6 & 17.3 & 18.7 \\
Become detached & 13.8 & 13.4 & 13.6 \\
Become no longer detached & 8.9 & 7.8 & 8.3 \\
& & & \\
Un-weighted total & 1,778 & 2,247 & 4,025 \\
\hline
\end{tabular}


Table 3. Descriptive sample characteristics

\begin{tabular}{|c|c|c|}
\hline Variable & Men (\%) & Women (\%) \\
\hline \multicolumn{3}{|l|}{ Age group: } \\
\hline $52-59$ & 48.2 & 45.0 \\
\hline $60-69$ & 32.8 & 32.1 \\
\hline $70-79$ & 16.9 & 18.9 \\
\hline $80+$ & 2.1 & 4.0 \\
\hline \multicolumn{3}{|l|}{ Education: } \\
\hline Low & 50.3 & 50.1 \\
\hline Medium & 32.5 & 37.9 \\
\hline High & 17.2 & 12.0 \\
\hline \multicolumn{3}{|l|}{ Household wealth (quintiles): } \\
\hline Poorest & 11.6 & 14.9 \\
\hline 2 & 17.6 & 18.8 \\
\hline 3 & 20.2 & 20.8 \\
\hline 4 & 24.9 & 21.6 \\
\hline Richest & 25.7 & 24.0 \\
\hline \multicolumn{3}{|l|}{ Change in marital status w1-w3: } \\
\hline Couple both waves & 82.0 & 63.7 \\
\hline Single both waves & 4.8 & 3.9 \\
\hline Separated both waves & 4.8 & 8.3 \\
\hline Widowed both wave & 4.2 & 16.7 \\
\hline Became widowed & 2.3 & 4.8 \\
\hline Became separated & 0.7 & 1.2 \\
\hline Became coupled & 1.2 & 1.4 \\
\hline \multicolumn{3}{|c|}{ Change in employment status w1-w3: } \\
\hline Retired both waves & 41.2 & 37.5 \\
\hline Employed both waves & 33.5 & 22.9 \\
\hline Other both waves & 4.5 & 10.6 \\
\hline Retired from employed & 11.1 & 9.1 \\
\hline Retired from other & 3.6 & 8.8 \\
\hline Working from other or retired & 3.7 & 3.6 \\
\hline Other from working or retired & 2.5 & 7.6 \\
\hline \multicolumn{3}{|l|}{ Self-reported health: } \\
\hline Very good & 35.9 & 32.9 \\
\hline Good & 42.8 & 43.0 \\
\hline Fair & 17.1 & 19.0 \\
\hline Bad & 4.2 & 5.2 \\
\hline \multicolumn{3}{|c|}{ Change in self-reported health w1-w3: } \\
\hline Better & 16.6 & 17.6 \\
\hline Same & 53.2 & 55.2 \\
\hline Worse & 30.2 & 27.2 \\
\hline \multicolumn{3}{|l|}{ Place of residence: } \\
\hline Urban & 74.1 & 73.5 \\
\hline Town & 12.2 & 12.9 \\
\hline Rural & 13.8 & 13.6 \\
\hline Access to a car & 92.4 & 86.0 \\
\hline No access to a car & 7.6 & 14.0 \\
\hline Un-weighted N & 1,778 & 2,247 \\
\hline
\end{tabular}


Table 4a. Multinomial logistic regression of change social detachment, men 2006-10

\begin{tabular}{|c|c|c|c|c|c|c|c|c|c|}
\hline \multirow{2}{*}{$\begin{array}{l}\text { Variable } \\
\text { Age group: }\end{array}$} & \multicolumn{3}{|c|}{ Detached both waves } & \multicolumn{3}{|c|}{ Become detached } & \multicolumn{3}{|c|}{ No longer detached } \\
\hline & \multirow{2}{*}{$\begin{array}{l}\text { RRR } \\
1.00\end{array}$} & \multicolumn{2}{|c|}{$95 \% \mathrm{Cl}$} & RRR & \multicolumn{2}{|c|}{$95 \% \mathrm{Cl}$} & RRR & \multicolumn{2}{|c|}{$95 \% \mathrm{Cl}$} \\
\hline 52-age & & & & 1.00 & & & 1.00 & & \\
\hline $60-69$ & 1.11 & 0.73 & 1.70 & 0.92 & 0.56 & 1.52 & 1.10 & 0.62 & 1.96 \\
\hline $70-79$ & 2.59 & 1.52 & 4.40 & 1.55 & 0.86 & 2.78 & 1.47 & 0.69 & 3.14 \\
\hline $80+$ & 4.30 & 1.69 & 10.90 & 1.26 & 0.38 & 4.15 & 1.42 & 0.26 & 7.70 \\
\hline \multicolumn{10}{|l|}{ Education: } \\
\hline Low & 1.00 & & & 1.00 & & & 1.00 & & \\
\hline Medium & 0.44 & 0.32 & 0.62 & 0.78 & 0.55 & 1.12 & 0.67 & 0.43 & 1.03 \\
\hline High & 0.43 & 0.27 & 0.66 & 0.55 & 0.34 & 0.88 & 0.36 & 0.19 & 0.68 \\
\hline Household wealth (quintiles) & 0.77 & 0.68 & 0.88 & 0.86 & 0.75 & 0.98 & 0.78 & 0.66 & 0.92 \\
\hline \multicolumn{10}{|l|}{ Change in marital status w1-w3: } \\
\hline Couple both waves & 1.00 & & & 1.00 & & & 1.00 & & \\
\hline Single both waves & 3.11 & 1.67 & 5.79 & 1.22 & 0.55 & 2.69 & 0.58 & 0.19 & 1.78 \\
\hline Separated both waves & 1.07 & 0.58 & 2.01 & 1.21 & 0.61 & 2.41 & 0.55 & 0.18 & 1.65 \\
\hline Widowed both wave & 0.96 & 0.51 & 1.84 & 1.16 & 0.58 & 2.33 & 1.01 & 0.36 & 2.85 \\
\hline Became widowed & 0.90 & 0.37 & 2.21 & 0.84 & 0.30 & 2.35 & 1.53 & 0.57 & 4.07 \\
\hline Became separated & 1.67 & 0.46 & 6.07 & 0.00 & 0.00 & 0.00 & 0.85 & 0.10 & 7.21 \\
\hline Became coupled & 1.19 & 0.41 & 3.52 & 0.42 & 0.07 & 2.44 & 1.23 & 0.17 & 8.94 \\
\hline \multicolumn{10}{|l|}{ Change in employment status w1-w3: } \\
\hline Retired both waves & 1.00 & & & 1.00 & & & 1.00 & & \\
\hline Employed both waves & 1.79 & 1.10 & 2.92 & 0.95 & 0.54 & 1.68 & 2.45 & 1.29 & 4.66 \\
\hline Other both waves & 1.89 & 0.83 & 4.31 & 1.00 & 0.41 & 2.48 & 1.97 & 0.62 & 6.22 \\
\hline Retired from employed & 1.40 & 0.83 & 2.37 & 0.59 & 0.30 & 1.14 & 1.67 & 0.88 & 3.17 \\
\hline Retired from other & 1.10 & 0.50 & 2.42 & 0.87 & 0.38 & 1.96 & 1.04 & 0.34 & 3.16 \\
\hline Working from other or retired & 1.42 & 0.64 & 3.15 & 0.35 & 0.10 & 1.26 & 1.68 & 0.57 & 4.95 \\
\hline Other from working or retired & 2.03 & 0.92 & 4.47 & 0.61 & 0.20 & 1.89 & 0.00 & 0.00 & 0.00 \\
\hline Self-reported health problems & 1.48 & 1.20 & 1.84 & 1.48 & 1.19 & 1.83 & 1.30 & 0.98 & 1.72 \\
\hline Decline in self-reported health w1-w3 & 1.26 & 1.04 & 1.53 & 1.46 & 1.18 & 1.80 & 1.05 & 0.80 & 1.38 \\
\hline \multicolumn{10}{|l|}{ Place of residence: } \\
\hline Urban & 1.00 & & & 1.00 & & & 1.00 & & \\
\hline Town & 1.21 & 0.80 & 1.81 & 1.20 & 0.76 & 1.91 & 0.87 & 0.48 & 1.59 \\
\hline Rural & 1.69 & 1.15 & 2.50 & 1.68 & 1.11 & 2.55 & 1.41 & 0.83 & 2.40 \\
\hline Access to a car & 1.00 & & & 1.00 & & & 1.00 & & \\
\hline No access to a car & 1.46 & 0.80 & 2.66 & 2.16 & 1.11 & 4.20 & 3.19 & 1.50 & 6.75 \\
\hline
\end{tabular}

Notes: table shows relative risk ratios (RRR) and $95 \%$ confidence intervals $(\mathrm{Cl})$. The reference category is not detached at either wave. Sample size 1,778 . Bold indicates significant estimates at $5 \%$ level. 
Table 4b. Multinomial logistic regression of change social detachment, women 2006-10

Variable

Age group:

52-59

60-69

70-79

$80+$

Education:

Low

Medium

High

Household wealth (quintiles)

Change in marital status w1-w3:

Couple both waves

Single both waves

Separated both waves

Widowed both wave

Became widowed

Became separated

Became coupled
Detached both waves

RRR $\quad 95 \% \mathrm{Cl}$

1.00

1.11

2.86

4.54

0.75

1.64

1.76

4.65

9.74
Become detached

RRR $\quad 95 \% \mathrm{Cl}$

1.00

$\begin{array}{lll}1.21 & 0.82 & 1.78\end{array}$

$\begin{array}{lll}2.27 & 1.38 & 3.71\end{array}$

$\begin{array}{lll}4.37 & 1.99 & 9.63\end{array}$
No longer detached RRR $\quad 95 \% \mathrm{Cl}$

1.00

$\begin{array}{lll}0.93 & 0.56 & 1.55\end{array}$

$\begin{array}{lll}1.34 & 0.71 & 2.51\end{array}$

$\begin{array}{lll}0.91 & 0.23 & 3.58\end{array}$
1.00

$\begin{array}{lll}0.65 & 0.47 & 0.89\end{array}$

$\begin{array}{lll}0.19 & 0.10 & 0.36\end{array}$

$\begin{array}{lll}\mathbf{0 . 1 8} & 0.09 & 0.33\end{array}$

$\begin{array}{lll}\mathbf{0 . 8 0} & 0.71 & 0.89\end{array}$

1.00

1.12

0.57

2.17

0.63

$0.38 \quad 1.06$

$\begin{array}{lll}0.66 & 0.44 & 0.98\end{array}$

$\begin{array}{lll}\mathbf{0 . 3 9} & 0.18 & 0.85\end{array}$

$\begin{array}{lll}1.47 & 0.54 & 3.98\end{array}$

$\begin{array}{lll}1.16 & 0.36 & 3.67\end{array}$
1.00

$\begin{array}{lll}1.06 & 0.50 & 2.24\end{array}$

$\begin{array}{llll}\mathbf{0 . 5 7} & 0.34 & 0.97\end{array}$

$\begin{array}{lll}0.68 & 0.43 & 1.06\end{array}$

$\begin{array}{lll}0.56 & 0.28 & 1.11\end{array}$

$\begin{array}{lll}0.81 & 0.23 & 2.87\end{array}$

$\begin{array}{lll}1.18 & 0.41 & 3.41\end{array}$
1.00

$\begin{array}{lll}\mathbf{0 . 5 7} & 0.39 & 0.83\end{array}$

$\begin{array}{lll}0.26 & 0.13 & 0.52\end{array}$

$\begin{array}{lll}0.77 & 0.67 & 0.89\end{array}$

Change in employment status w1-w3:

Retired both waves

1.00

1.00

1.00

Employed both waves

$\begin{array}{lll}1.67 & 1.01 & 2.78\end{array}$

$\begin{array}{lll}1.04 & 0.63 & 1.71\end{array}$

$\begin{array}{lll}1.78 & 0.99 & 3.19\end{array}$

$\begin{array}{lll}1.62 & 1.00 & 2.63\end{array}$

$\begin{array}{lll}1.09 & 0.64 & 1.87\end{array}$

$\begin{array}{lll}1.52 & 0.77 & 3.01\end{array}$

$\begin{array}{lll}1.58 & 0.88 & 2.81\end{array}$

$\begin{array}{lll}1.51 & 0.87 & 2.59\end{array}$

$\begin{array}{lll}1.07 & 0.53 & 2.20\end{array}$

$\begin{array}{lll}1.40 & 0.86 & 2.28\end{array}$

$\begin{array}{lll}0.74 & 0.41 & 1.34\end{array}$

$\begin{array}{lll}0.75 & 0.37 & 1.52\end{array}$

$\begin{array}{lll}2.01 & 0.95 & 4.24\end{array}$

$\begin{array}{lll}1.43 & 0.63 & 3.27\end{array}$

$\begin{array}{lll}0.50 & 0.14 & 1.80\end{array}$

$\begin{array}{lll}1.24 & 0.73 & 2.11\end{array}$

$\begin{array}{lll}0.92 & 0.52 & 1.65\end{array}$

$\begin{array}{lll}1.05 & 0.52 & 2.14\end{array}$

Self-reported health problems

$\begin{array}{lll}2.08 & 1.72 & 2.51\end{array}$

$\begin{array}{lll}1.37 & 1.10 & 1.69\end{array}$

$\begin{array}{lll}1.28 & 1.00 & 1.62\end{array}$

Decline in self-reported health w1-w3

$\begin{array}{lll}1.47 & 1.21 & 1.78\end{array}$

$\begin{array}{lll}1.36 & 1.11 & 1.67\end{array}$

$\begin{array}{lll}0.98 & 0.76 & 1.27\end{array}$

Place of residence:

Urban

1.00

Town

$\begin{array}{lll}1.23 & 0.85 & 1.79\end{array}$

1.00

1.00

Rural

$\begin{array}{lll}1.77 & 1.24 & 2.53\end{array}$

$\begin{array}{lll}0.89 & 0.57 & 1.37\end{array}$

$\begin{array}{lll}0.92 & 0.55 & 1.54\end{array}$

$\begin{array}{lll}1.20 & 0.76 & 1.87\end{array}$

$\begin{array}{lll}1.07 & 0.65 & 1.76\end{array}$

Access to a car

1.00

1.00

1.00

No access to a car

$\begin{array}{lll}1.27 & 0.84 & 1.90\end{array}$

$\begin{array}{lll}1.14 & 0.75 \quad 1.76\end{array}$

$\begin{array}{lll}0.99 & 0.54 \quad 1.80\end{array}$ 
Figure 1. Distribution of social activity engagement, wave 3 (2006/07)

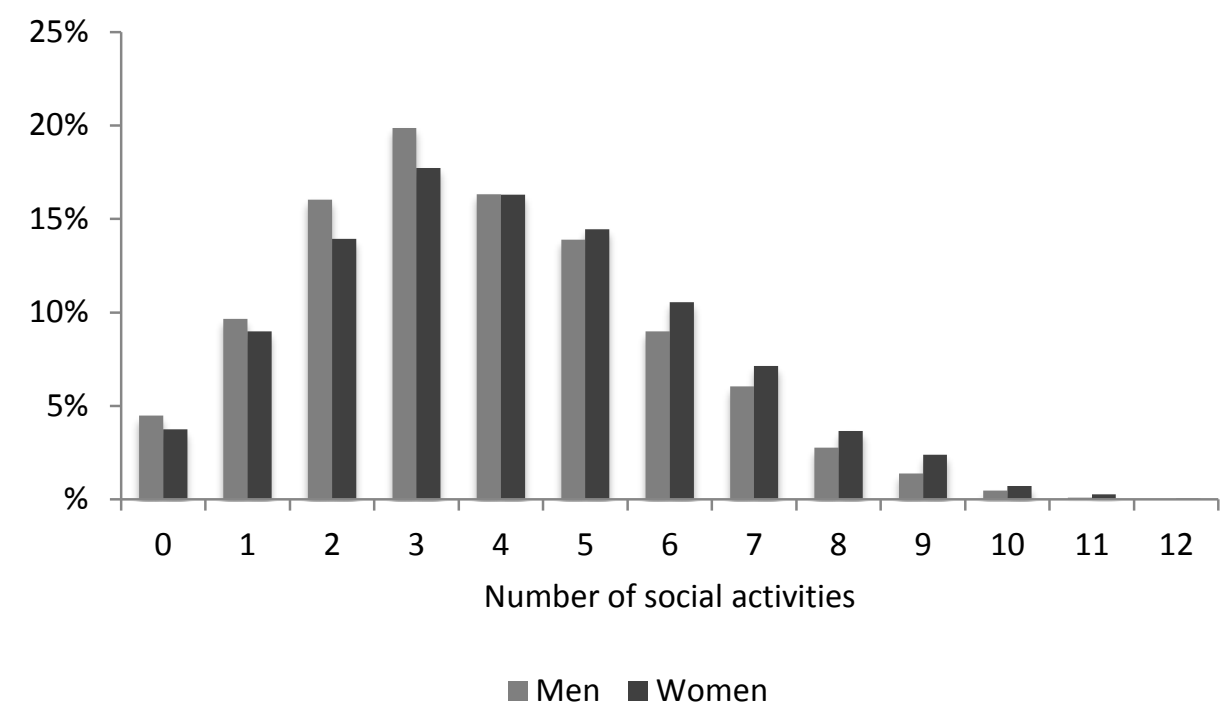

